\title{
SUPPLIER SELECTION FOR COLLABORATIVE NEW PRODUCT DEVELOPMENT PROCESS: AN APPLICATION TO THE AUTOMOTIVE INDUSTRY ${ }^{1}$
}

\author{
Maria Jose Verdecho*, Juan Jose Alfaro and Raul Rodriguez-Rodriguez \\ Department of Business Organisation \\ CIGIP (Research Centre on Production Management and Engineering) \\ Universidad Politécnica de Valencia \\ Valencia, Spain \\ E-mail: \{mverdecho, jalfaro, raurodro\}@cigip.upv.es
}

\begin{abstract}
In the last few years, there has been an increasing growth in the number of collaborative partnerships between suppliers and manufacturers as a means to meet more complex customer needs and remain competitive. Selecting suppliers for a collaborative new product development (CNPD) process is a multicriteria decision making problem involving both qualitative and quantitative factors. The aim of this paper is to identify the qualitative and quantitative criteria for selecting suppliers for a CNPD process and to provide a decision tool for evaluating and ranking potential suppliers. The main criteria are both operational and relational competencies of the suppliers that comprise three dimensions: product, structure and interaction dimensions. The multi-criteria decision analysis method used to evaluate and rank suppliers is the Analytic Hierarchy Process (AHP). The AHP model is presented in a real application to a global first-tier manufacturing company belonging to the automotive industry in Spain. Finally, results of the application are discussed.
\end{abstract}

Keywords: collaborative new product development, analytic hierarchy process, automotive industry

\section{Introduction}

Global competition, rapidly changing technologies, reduced product lifecycles, cost reduction, high quality products and more demanding end customers are some of the factors that have made companies to look for new strategies for developing new products. New product development (NPD) process includes all the activities from the development of an idea or a concept for a product, to the realization of the product during the production stage and its introduction into the market place. In general, the NPD process comprises different stages until the product is launched such as planning, product design and development, process design and development, and product and process validation (Advanced Product Quality, 1995). The importance of the NPD process is widely acknowledged. Therefore, it is not surprising that some works suggest that 'if new products are the lifeblood of a corporation, then product development is the lifeblood of a company's new products' (Lambert and Cooper, 2000).

In the last years, there has been an increasing growth in the number of collaborative partnerships for NPD between suppliers and manufacturers. Congruent with the need to integrate multiple linked processes in the supply chain, theoretical research advocate that early and extensive supplier involvement results in

\footnotetext{
${ }^{1}$ This work stems from the participation of the authors in a research project funded by the Polytechnic University of Valencia, reference PAID-06-08-3206, and titled "Design and Implementation of Performance Measurement Systems within Collaborative Contexts for aiding the Decision-making Process".

${ }^{*}$ Corresponding author
} 
many benefits, e.g. faster development process (Petersen, Handfield, and Ragatz, 2005). In this context, selecting suppliers for collaborative NPD (CNPD) becomes a crucial process for manufacturers.

The muti-attribute nature of the process of supplier selection has been widely studied in the literature focusing attention on two main issues: the identification of criteria for the assessment, and the application of multi-attribute techniques to pass from the initial criteria to an overall ranking of suppliers (Masella and Rangone, 2000). In addition, supplier selection involves considering both qualitative and quantitative criteria (Chan and Kumar, 2007). Therefore, selecting suppliers for CNPD can be defined as a multicriteria decision making $(\mathrm{MCDM})$ problem involving both qualitative and quantitative factors.

The purpose of this paper is to identify the required criteria for selecting the best supplier for CNPD process and provide a supplier selection decision model including these criteria by using the analytic hierarchy process (AHP). In addition, an application of this approach to a real case within the Spanish automotive industry is presented.

The structure of this paper is as follows. The next section presents the background. Section 3 explores the AHP model for CNPD supplier selection. Section 4 develops an application of the AHP model within the Spanish automotive industry. Finally, conclusions are given.

\section{Background: AHP for supplier selection}

Several methods have been proposed for solving the supplier selection problem such as vendor profile analysis (VPA), multi-objetive programming (MOP), data envelopment analysis (DEA) and analytic hierarchy process (AHP) (Chan and Kumar, 2007). Evaluation and ranking of potential suppliers involves both tangible and intangible criteria. This is because overall assessment of suppliers should not only consider quantitative performance data but also some other criteria that are critical for successful parnerships and are not directly quantifiable, e.g. trust and commitment (Mohr and Spekman, 1996). Therefore, the AHP method developed by Saaty (1980) is a useful method to select suppliers as it deals with both types of criteria. In addition, AHP aims at integrating different measures into a single overall score for ranking decision alternatives (Rangone, 1996).

The AHP method has been previously used for supplier selection under a wide variety of applications (Perçin, 2006). Ghodsypour and O'Brien (1998) present an integrated AHP and linear programming method for choosing the best suppliers and placing the optimum order quantities among them. Masella and Rangone (2000) propose four different vendor selection systems (VSSs) depending on the time frame (short-term versus long-term) and the content (logistic versus strategic) of the co-operative customer/supplier relationships using an AHP framework. Akarte, Surendra, Ravi, and Rangaraj (2001) propose an AHP model for casting supplier assessment based on four groups of criteria: product development capability, manufacturing capability, quality capability, and cost and delivery. Al-Harbi (2001) applied AHP in the field of project management to select the best contractor to perform the project based on six criteria: experience, financial stability, quality performance, manpower resources, equipment resources, and current workload. Muralidharan, Anantharaman, and Deshmukh (2002) develop a multicriteria group decision making model for supplier ranking based on AHP by combining group member's preferences into one consensus ranking. The criteria used to rate suppliers are quality, delivery, price, technical capability, financial position, past performance attitude, facilities, flexibility and service. Huan, Sheoran, and Wang (2002) propose an AHP model to structure SCOR (supply chain operations reference) model metrics to evaluate overall supplier efficiency. Kahraman, Cebici, and Ulukan (2003) present a multi-criteria supplier selection procedure using fuzzy AHP. The first level criteria used to compare suppliers involve: supplier, product and service criteria. Chan and Kumar (2007) propose a fuzzy-AHP approach to select global suppliers according to five criteria: cost, quality, service performance, supplier 
profile and risk factor. Regarding the CNPD process, AHP has been used in few applications such as in Lam and Chin (2005) and Lam, Chin, Yang, and Liang (2007) that suggest an AHP model for the selfassessment of conflict management in client-supplier collaborative new product development. In addition, AHP has been used for other applications within CNPD process such as priorization of criteria and preferences of NPD mixes in a network with strategic partners under uncertainty (Chen, Lee, and Tong, 2007). However, there is not a specific AHP model developed for selecting suppliers for CNPD. For this reason, the purpose of the remaining of this paper is to present an AHP model for supplier selection for CNPD and its application to the Spanish automotive industry.

\section{The AHP model for CNPD supplier selection}

The AHP method structures the decision problem in a hierarchy of levels. These levels are linked by unidirectional dependence relationships. In the upper level of the hierarchy, the ultimate goal of the decision problem is located. Then, the criteria that contribute to achieve the goal stand in the second level. The third level is composed of attributes linked to each criterion defined in the second level. Finally, the decision alternatives are set in the lower level. Using levels allows decision makers to focus on a small set of decisions (Saaty, 1980). By making pairwise comparisons and using the fundamental scale of Saaty (1980), the AHP method provide relative weights to each element within a level depending on its contribution to an element linked to it that is located on the immediate upper level. After that, the overall priorities of alternatives in relation to the ultimate goal are calculated. In addition, sensitivity analysis of the solution can be performed to study if the solution obtained is robust.

In order to apply the AHP method, four phases have been established. In the first phase, the criteria and attributes for rating suppliers for CNPD involvement are identified and defined. Then, the AHP structure that represents the problem to be solved is composed. Once the AHP model is obtained, the second phase consists of making pairwise comparisons to obtain the relative priorities among: 1) criteria with regard to the main goal, 2) attributes with regard to main criteria and 3) decision alternatives (suppliers) with regard to attributes (that belong to a specific criterion and, consequently, support reaching the main goal). Once the relative priorities are obtained, the third phase aims at calculating the overall priorities of the decision alternatives. Finally, the fourth phase deals with sensitivity analysis of the solution provided. The description of the phases is described as follows.

\subsection{Phase 1. Identify the main criteria for selecting suppliers and compose the hierarchical AHP model}

Croom (2001) suggest a conceptual framework for supplier involvement in collaborative product development from a study in the UK auto industry. The framework considers both operational and relational competencies and comprises three dimensions or criteria: product, structure and interaction. Based on Croom's work, this section exposes the description of criteria as well as their related attributes in order to compose the AHP model.

The product criterion comprises the main attributes that are to be addressed when assessing the product dimension of the supplier. These attributes are: quality, price, development time, flexibility, and research and development (R\&D) initiatives.

Quality is one of the most important product attributes. It relates to the historical rejection rate during a period of time of the products delivered by the supplier. Rejection is due to deviations from specifications in the design, manufacturing, or packaging of the product. These non-conforming parts can be detected during incoming inspection or manufacturing in customer locations. It also considers deviations from the specified quantities or delivery dates in the customer order. Cost is an important attribute of the product as it affects the bottom-line. It involves the manufacturing cost, packaging cost, delivery cost and costs related to non-conforming product delivered to the manufacturer. Development time refers to the 
competence of the supplier to design, develop and launch products within the agreed period of time according to the product specifications. In the current competitive environment, it is a crucial attribute to assess suppliers as delays in development stage can affect the end customer response during the launching stage. Flexibility involves the response time of the supplier when engineering changes are needed during the development stage. It also considers the response time to new orders or order modifications during the development and manufacturing stages. Finally, $R \& D$ initiatives measure the ability of the supplier to provide support during product development and manufacturing. It is an important attribute as most products, after launching, demand continuous improvement to remain competitive.

The second criterion is structure. Structure comprises the capabilities/procedures for developing products and processing materials/components as well as the systems to facilitate control, co-ordination and communication through organizational and interorganizational systems.

The first attribute within the structure criterion is dedicated cross-functional team which assesses the human compromised capabilities of the supplier into the relationship in the areas involved in the NPD stage such as product and process design and quality development. The second attribute is project management methodology which measures the degree of knowledge and implementation of project management practices in the supplier organization as well as the compatibility with the project management practices of the manufacturer. The third attribute is quality methodologies. It measures the degree of knowledge and implementation of quality practices (DFMEA, PFMEA, QFD, etc.) in the supplier organization in order to facilitate new product development, launching and manufacturing. The fourth attribute is Information Technology and Information Systems (IT \& IS). It assesses the extent of technology implementation and interoperability of supplier information systems in order to send/receive and use the information exchanged between supplier and manufacturer. The role of the technology is an important attibute as effective collaboration as it is highly influenced by seamless communication between supplier and manufacturer. The fifth attribute is process alignment. It evaluates the extent of business process interoperability defined as the "ability of different processes to work together and exchange information, data, control information, etc." (Interop, 2008). The sixth attribute is complementary capabilities. It measures the degree of interdependence on assets as well as the capacity on development/manufacturing so that the collaborative relationship can develop and manufacture higher variety/amount of products to increase the market share. Finally, the financial profile attribute assesses the past and current financial condition of the supplier in order to support/invest in the long-term.

The third criterion is the interaction criterion which deals with the relational side of collaboration. Based on Mohr and Spekman (1996), the relational attributes considered in the AHP model are: coordination, commitment, trust, information sharing, and conflict management.

Coordination involves the tasks that are to be taken for linking activities performed by the different members in a seamless manner. The coordination degree between manufacturer and supplier is an important attribute of the relationship as it allows moving together towards the achievement of mutual objectives. Commitment refers to the willingness of the supplier to perform effort on behalf of the relationship. It is the establishment of the foundation of the relationship and it is based on being supportive in solving problems together. A high level of commitment provides the context for the achievement of individual and mutual goals. Trust is based on the belief that the partner is reliable and will fullfil its responsibilities acting fairly. A partner trusts another partner if considers that decisions made by this last one will be in the interest of both parts. Information sharing considers the timeliness, accuracy, adequacy and completeness of the relevant information exchanged. Finally, conflict management measures the degree of intensity and conflict resolution mechanisms that exist between manufacturer and supplier. The existence of conflict is inherent to interpersonal as well as interorganizational relationships. However, the manner this conflict is managed is essential to the longterm and stability of the relationship. 

Industry

Figure 1 shows the four levels that compose the AHP model for partner selection for CNPD. The first level is the overall objetive. The second level comprises the criteria: product, structure and interaction. The third level is composed by the attributes related to each criterion. Finally, the potential suppliers (decision alternatives) are located in the fourth level.

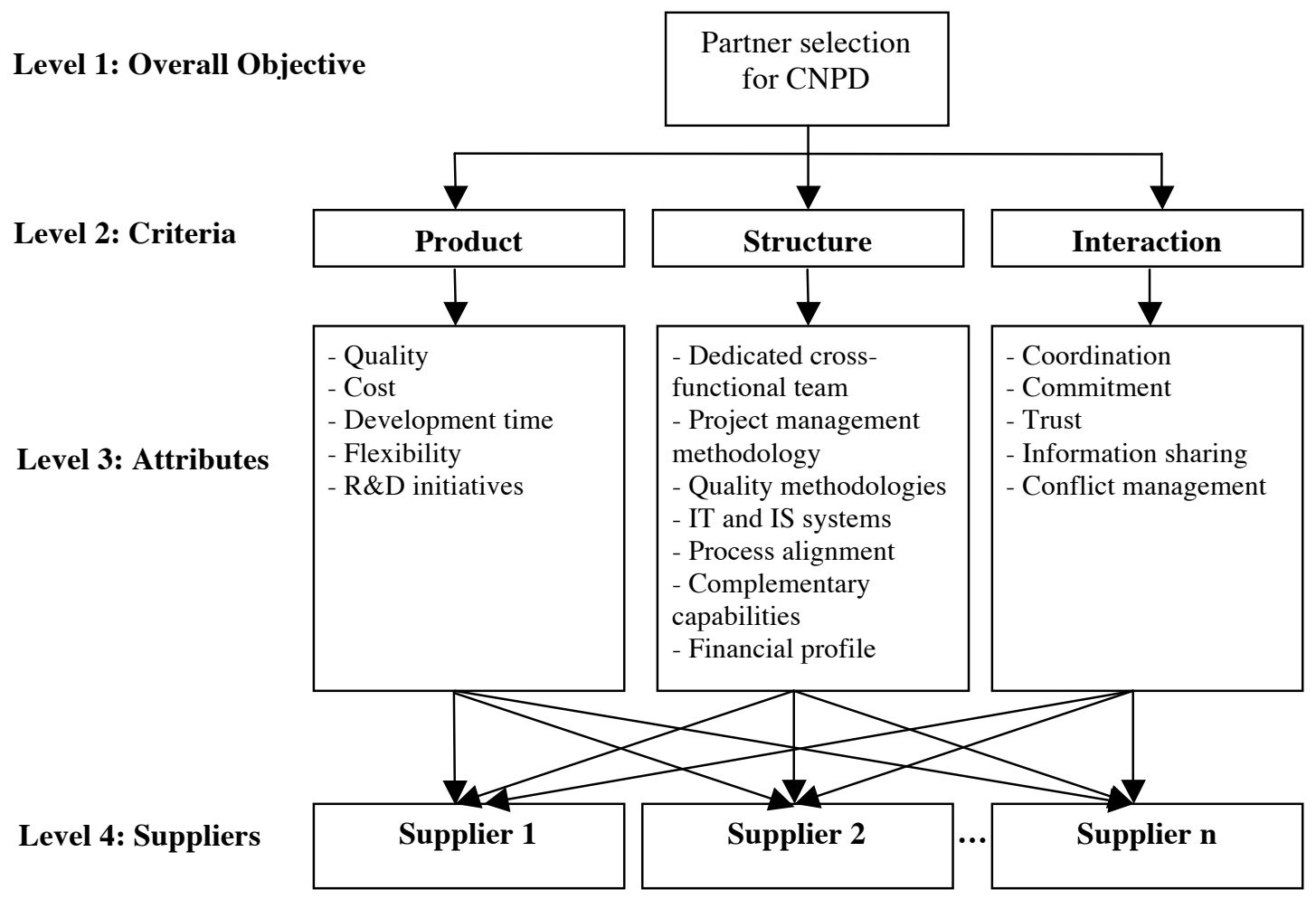

Figure 1. AHP partner selection model for CNPD process

\subsection{Phase 2. Pairwise comparison matrices}

Once criteria are defined and the hierarchical structure is obtained, the decision makers give preference among elements in each level (criteria, attributes and alternatives) by making pairwise comparisons. These comparisons indicate the relative importance of one element versus another element with regard to an element that both elements are linked located on an immediate upper level. These comparisons are introduced on matrices called pairwise comparison matrices. After pairwise comparisons matrices are completed, the local priorities of the compared elements (priority vector) are calculated and consistency of judgements checked.

\subsection{Phase 3. Synthesis}

Once all priority vectors are obtained and consistency verified, the overall priorities for the alternatives are calculated. For that purpose, priorities of decision alternatives are combined together with the sets of priorities of criteria and attributes.

\subsection{Phase 4. Sensitivity Analysis}

In this phase, it is analysed how changes in the local weights of one of the criteria, attributes or alternatives affect the overall priorities previously obtained. The purpose of this phase is to verify that the solution obtained as the preferred alternative is robust enough. 


\section{Case study}

The focal company of this application is a manufacturer of injection moulding finished parts for the automotive industry in Spain. The manufacturer is a global first-tier supplier of the main car manufacturers (Ford, General Motors, Renault, Volvo, Nissan, etc.) having design centres and manufacturing plants in Europe, North America, South America and Asia. During the last ten years, the European purchasing department has been applying the policy of reducing the number of suppliers for some of the main components, dividing the total amount of these components to be purchased into two or three main suppliers. However, due to the success of a new product launched in 2006, and the new market needs regarding this new product, the company pursues to change the policy and select one main supplier to establish a collaborative relationship for the NPD process. Particularly, one of the components of this product is critical as the technology and know-how required to design it and manufacture it is not a core capability of the manufacturer. The three suppliers currently delivering this component have the capability and know-how to manufacture the component and, therefore, are potential candidates for the selection. Thus, the problem is to select the best supplier as single source (Ghodsypour and O'Brien, 1998). Three managing directors of the manufacturer responsible for purchasing, new product management and operations were in charge of the assessment of the suppliers.

From the AHP model showed in Figure 1, the decision makers prioritise the criteria, attributes and alternatives by making pairwise comparisons (Phase 2). For that purpose, the software Web-Hipre (Mustajoki and Hämäläinen, 2000) was used. Figure 2 shows the pairwise comparison matrix for the criteria with respecto to the selection goal.

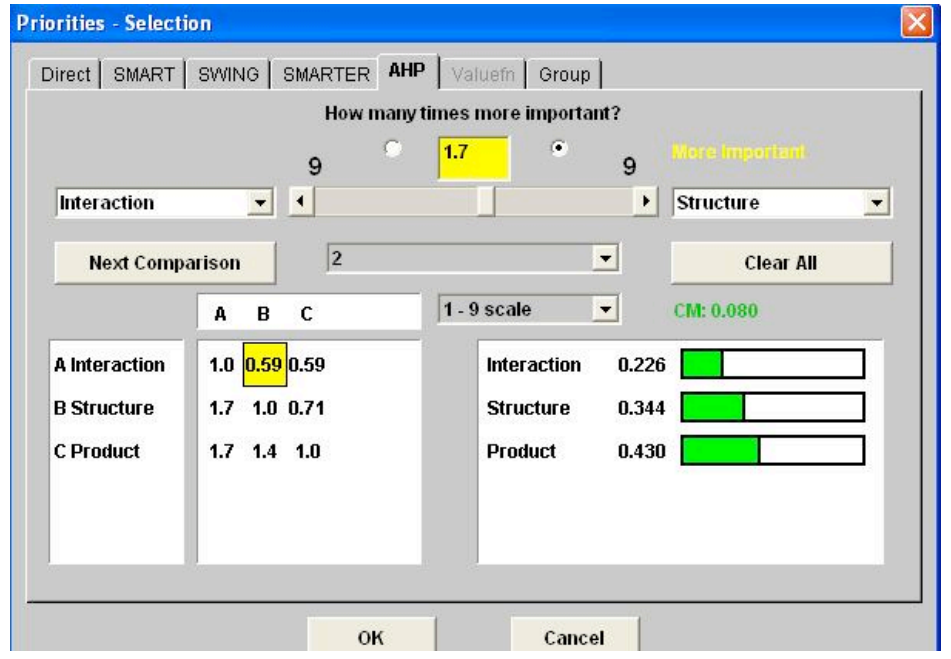

Figure 2. Priorities of criteria

As can be observed on the bar graph, product is the most important criterion with a priority value of 0.430 . Then, structure criterion (0.344) is the second most important criterion, and finally, interaction criterion (0.266) has the third position. In addition, consistency of judgements has being checked. Fortunately, Web-hipre also allows verifying the consistency of judgements. In this case, as the consistency index is below 0.1 (concretely, 0.080 ), consistency of judgements is acceptable.

Figure 3 shows the pairwise comparison matrix of attributes for the criterion with highest local priority, product criterion. As can be observed, development time is the attribute with highest priority (0.371) but it is very close to R\&D initiatives (0.365). Then, the third most important attribute is flexibility (0.123). Finally, cost (0.083) and quality (0.058) rate lower positions. It is noticeable the differences in local 

Industry

priorities between the quality and cost attributes with respect to $R \& D$ inititiatives and development time attributes. Decision makers agree that this is due to the fact that quality and cost are attributes currently met for the specific component that suppliers are develivering to the manufacturer. However, development time and R\&D innitiatives attributes are to be improved. In fact, both characteristics are essential for the competitiveness of the manufacturer. In this case, consistency is 0.036. Therefore, judgements are consistent.

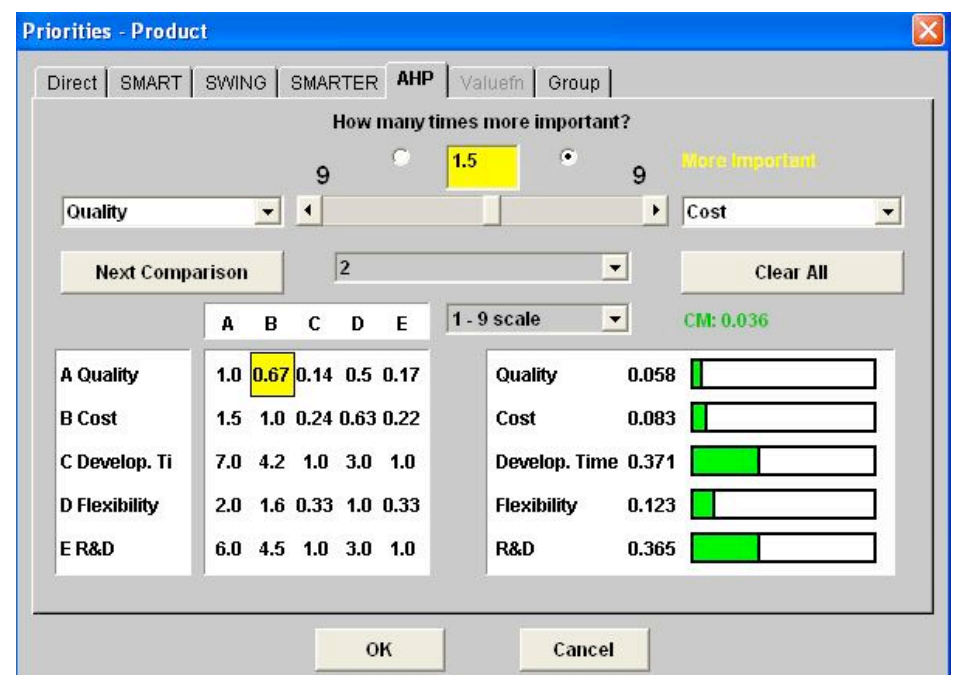

Figure 3. Priorities of attributes for the product criterion

Figure 4 shows the pairwise comparison matrix for suppliers regarding development time attribute which is the attribute with higher weight within the product criterion. Supplier 2 is the one with highest priority (0.502), followed by supplier $3(0.365)$ and supplier $1(0.133)$. Consistency is also acceptable $(0.034)$.

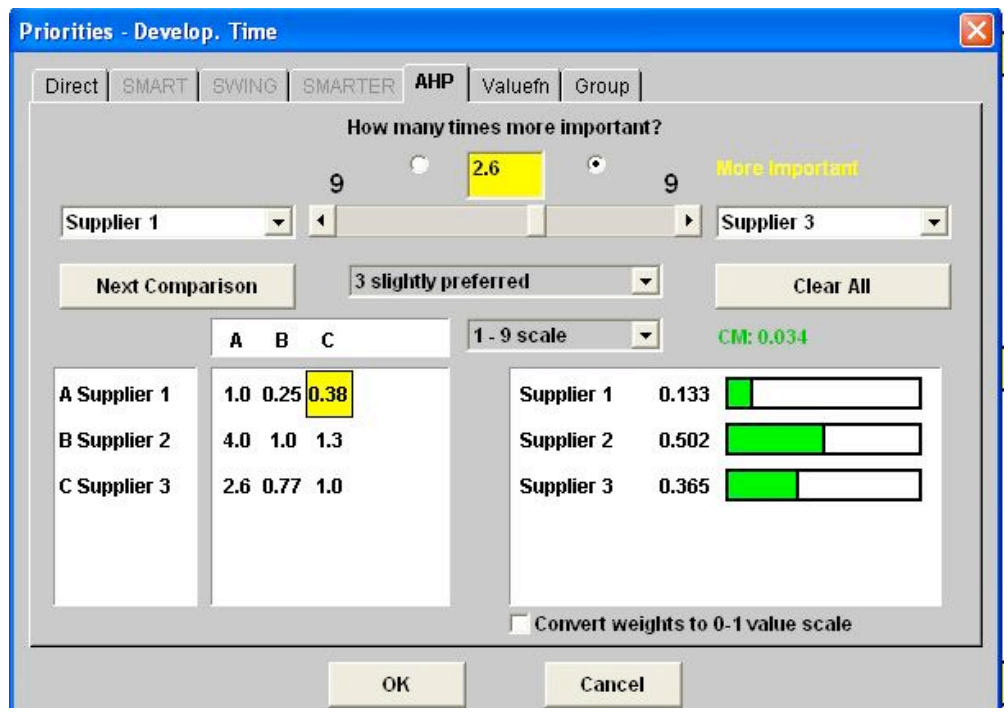

Figure 4. Priorities of suppliers for development time attribute

Once all the pairwise comparison matrices have been obtained and consistency checked, the overall priorities are calculated (Phase 3). Table 1 shows the overall priorities for the three suppliers. In addition, 
Figure 5 shows these priorities graphically. As a result, the preferred supplier is supplier 2 with an overall rating of 0.388 . Then, suppliers 3 and 1 are rated 0.310 and 0.301 respectively.

Table 1. Overall priorities for suppliers.

\begin{tabular}{|l|l|l|l|}
\hline & Supplier 1 & Supplier 2 & Supplier 3 \\
\hline Product & 0.114 & 0.176 & 0.140 \\
\hline Structure & 0.109 & 0.128 & 0.107 \\
\hline Interaction & 0.079 & 0.084 & 0.063 \\
\hline Overall & 0.302 & $\mathbf{0 . 3 8 8}$ & 0.310 \\
\hline
\end{tabular}

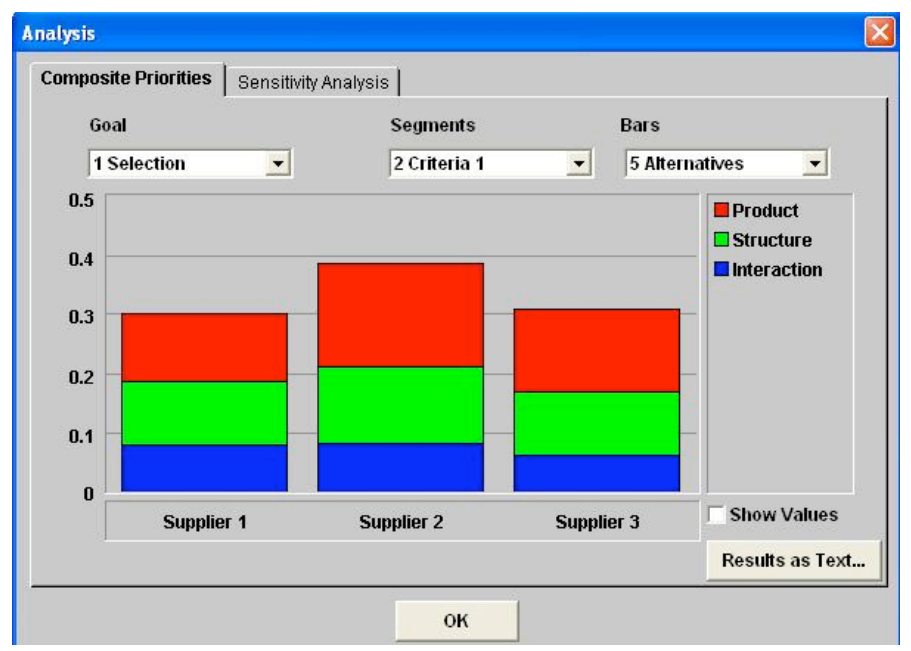

Figure 5. Overall priorities for suppliers

Once overall ratings are obtained, it is analysed how changes in the local weights of one of the criteria, attributes or alternatives affect the overall priorities previously obtained (Phase 4). Figure 6 shows the sensitivity analysis for the product criterion with respect to the overall objective. It has been selected this criterion because it is the one that has higher impact on the overall objective with a local priority value of 0.430. As can be seen, supplier 2 is the preferred supplier although supplier 3 is gaining attention. In addition, repeting this process for the other two criteria, it is observed that supplier 2 continues being the one with highest overall priority. These results have been validated by the decision makers so that supplier 2 has been finally selected. 


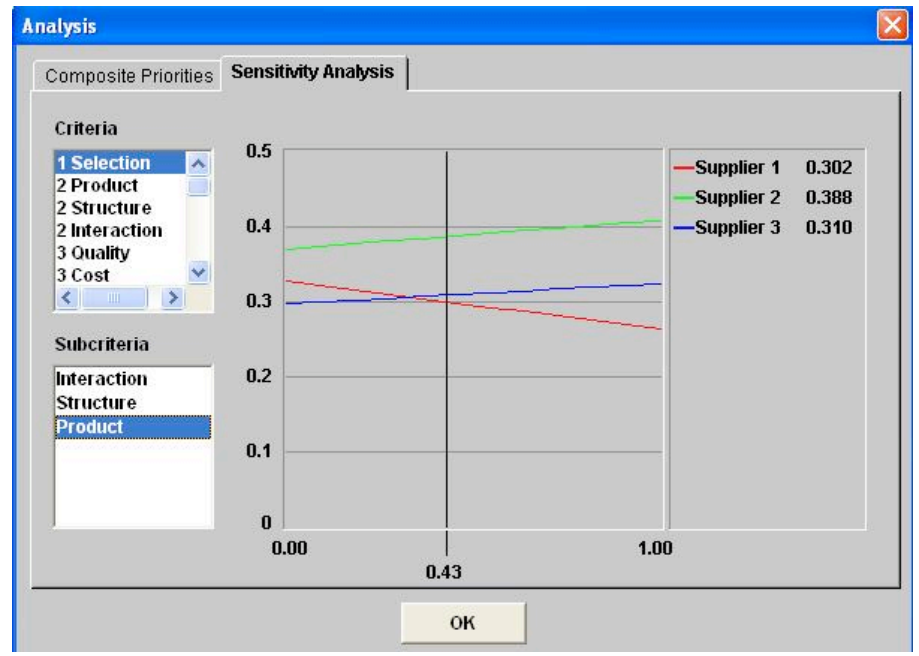

Figure 6. Sensitivity analysis for product criterion with respect to overall objective

\section{Conclusions}

In the current environment, customers demand products with high specifications, quality and competitive costs. In many industries such as the automotive industry, new product development is one of the core processes due to the fact that the success of this process will determine future market position within the industry. In the last years, many first-tier suppliers have been focusing on their core competencies and developing collaboration partnerships with other enterprises as a means to remain competitive. Supplier involvement results in many benefits, e.g. faster development process, access to new technologies, etc. For that reason, selecting suppliers for collaborative new product development is an essential process.

Supplier selection involves considering both qualitative and quantitative criteria as final performance will rely not only on the classical performance measures of the resulting products such as cost and quality but also on the effectiveness of the new product development process which is sustained by qualitative criteria. Thus, selecting suppliers for CNPD can be defined as a multi-criteria decision making problem involving both qualitative and quantitative factors. The AHP method is a useful method to select suppliers as it deals with both types of criteria. Concretely, this paper present three core dimensions to be considered when selecting suppliers for CNPD: product, structure and interaction dimensions. These core dimensions are further decomposed into seventeen attributes for approaching the selection process. Then, the AHP model is composed to select the best supplier.

The developed AHP model has been applied to the selection of a CNPD supplier for an injectionmoulding first-tier manufacturer within the Spanish automotive industry. The manufacturer has been working with three different suppliers delivering one main component for one of its current leading products. The market needs of this product demands more attention in technological and R\&D practices. Therefore, the company has decided to select one main supplier to establish a collaborative relationship for the NPD process. Although all three suppliers currently delivering this component are potential candidates for the selection, the best supplier has been selected with the aid of the AHP method. AHP method has proved to provide an adequate solution for the selection process as decision makers agree with the solution delivered.

\section{REFERENCES}

Advanced Product Quality (1995). Advanced Product Quality Planning and Control Plan Reference Manual. Chrysler Corporation, Ford Motor Company and General Motors Corporation. 
Akarte, M.M., Surendra, N.V., Ravi, B., \& Rangaraj, N. (2001). Web based casting supplier evaluation using analytical hierarchy process. Journal of the Operational Research Society, 52, 511-522.

Al-Harbi, K.M. (2001). Application of AHP in project management. International Journal of Project Management, 19, 4, 19-27.

Chan, F.T.S., \& Kumar, N. (2007). Global supplier development considering risk factors using fuzzy extended AHP-based approach. Omega, 35, 417-431.

Chen, H.H., Lee, A.H.I, \& Tong, Y. (2007). Prioritization and operations NPD mix in a network with strategic partners under uncertainty. Expert Systems with Applications, 33, 337-346.

Croom, S.R. (2001). The dyadic capabilities concept: examining the processes of key supplier involvement in collaborative product development. European Journal of Purchasing \& Supply Management, 7, 29-37.

Ghodsypour, S.H., \& O’Brien, C. (1998). A decision support system for supplier selection using an integrated analytic hierarchy process and linear programming. International Journal of Production Economics, 56-57, 199-212.

Huan, S.H, Sheoran, S.K. \& Wang, G. (2004). A review and analysis of supply chain operations reference (SCOR) model. Supply Chain Management: An International Journal, 9, 9, 23-29.

Interop. (2008). Interoperability ontology. Interop-vlab platform. Retrieved October 28, 2008, from: http://interop-vlab.eu/

Kahraman, C., Cebeci, U., \& Ulukan, Z. (2003). Multi-criteria supplier selection using fuzzy AHP. Logistics Information Management, 16, 6, 382-394

Lam, P.K. \& Chin, K.S. (2005). Identifying critical success factors for conflict management in collaborative new product development. Industrial Marketing Management, 34, 761-72.

Lam, P.K., Chin, K.S., Yang, J.B., \& Liang, W. (2007). Self-assessment of conflict management in clientsupplier collaborative new product development. Industrial Management \& Data Systems, 107, 5, 688714.

Lambert, D.M., \& Cooper, M.C. (2000). Issues in Supply Chain Management. Industrial Marketing Management, 29, 65-83.

Masella, C, \& Rangone, A. (2000). A contigent approach to the design of vendor selection systems for different types of co-operative customer/ supplier relationships. International Journal of Operations \& Production Management, 20, 1, 70-84.

Mohr, J.J., \& Spekman, R.E. (1996). Perfecting partnerships. Marketing Management, 4, 4, 34-43.

Muralidharan, C., Anantharaman, \& S.G. Deshmukh, S.G. (2002). A Multi-Criteria Group Decisionmaking Model for Supplier Rating. The Journal of Supply Chain Management: A Global Review of Purchasing and Supply, November, 22-33. 
Mustajoki, J., \& Hämäläinen, R.P. (2000). Web-Hipre: Global Decision Support by Value Tree and AHP Analysis. INFOR, 38, 3, 208-220.

Perçin, S. (2006). An application of the integrated AHP-PGP model in supplier selection. Measuring Business Excellence, 10, 4, 34-49.

Petersen, K.J., Handfield, R.B., \& Ragatz, G.L. (2005). Supplier integration into new product development: coordinating product, process and supply chain design. Journal of Operations Management, 23, 371-388.

Rangone, A. (1996). An analytical hierarchy process framework for comparing the overall performance of manufacturing departments. International Journal of Operations \& Production Management, 16, 8, 104119.

Saaty, T.L. (1980). The Analytic Hierarchy Process. New York, NY: McGraw-Hill. 